\title{
A method for rough estimation of the catalyst surface area in a fuel cell
}

\author{
Tanja Vidaković $\cdot$ Mihai Christov $\cdot$ Kai Sundmacher
}

Received: 27 March 2008/Accepted: 21 August 2008/Published online: 6 September 2008

(c) The Author(s) 2008. This article is published with open access at Springerlink.com

\begin{abstract}
A method for a rough estimation of the catalyst surface area in a fuel cell is developed. It is based on the deconvolution of experimental $\mathrm{CO}$ oxidation data by use of a mathematical model. The kinetic parameters of the model are determined by fitting the experimental curves. The experimental data are collected at different sweep rates $\left(2-100 \mathrm{mV} \mathrm{s}^{-1}\right)$ and at different temperatures (room $-60.0^{\circ} \mathrm{C}$ ). The model can predict the sweep rate dependence of the $\mathrm{CO}$ oxidation onset potential, the peak current, the peak potential and the peak broadness. The model is further used for the prediction of the baseline in the presence of $\mathrm{CO}$ and for calculation of the $\mathrm{CO}$ charge consumed up to half peak potential. It is obtained that the latter value is constant at different sweep rates and that the baseline deviates from linearity already at low sweep rates $\left(2 \mathrm{mV} \mathrm{s}^{-1}\right)$, but not very significantly ( $2.0 \%$ in comparison to $8.8 \%$ at $100 \mathrm{mV} \mathrm{s}^{-1}$, based on calculated CO charge). It is suggested that lower sweep rates should be used for experimental surface area determination.
\end{abstract}

Keywords Fuel cell · PtRu catalyst - Surface area · Mathematical model · Peak deconvolution

T. Vidaković $(\bowtie) \cdot K$. Sundmacher

Process Systems Engineering, Otto-von-Guericke-University

Magdeburg, Universitätsplatz 2, 39106 Magdeburg, Germany

e-mail: vidakovi@mpi-magdeburg.mpg.de

M. Christov

Department of Physical Chemistry, University of Chemical

Technology and Metallurgy, 1756 Sofia, Bulgaria

K. Sundmacher

Max-Planck-Institute for Dynamics of Complex Technical

Systems, Sandtorstr. 1, 39106 Magdeburg, Germany

\author{
Nomenclature \\ $B_{2 \theta} \quad$ Width of the X-ray diffraction peak at half \\ height/rad \\ $B_{2 \theta}^{\mathrm{r}} \quad$ Width of the X-ray diffraction peak at half height \\ for a standard compound/rad \\ $c_{\mathrm{DL} \_\mathrm{Me}} \quad$ Double layer capacitance of metal surface $/ \mathrm{mF}$ \\ $d \quad$ Average particle size/nm \\ $e \quad$ Elementary charge/C $\left(1.9 \times 10^{-19} \mathrm{C}\right)$ \\ E Potential/V \\ $E_{a, i}$ Activation energy for the surface reaction/ \\ $\mathrm{kJ} \mathrm{mol}^{-1}$ \\ $E_{\text {ini }} \quad \mathrm{CO}$ adsorption potential/ $\mathrm{V}$ \\ F Faraday constant/C mol${ }^{-1}\left(96,485 \mathrm{C} \mathrm{mol}^{-1}\right)$ \\ $c_{f} \quad$ Constant (Eq. 16)/- \\ $g_{i} \quad$ Heterogeneity/interaction factor of the ith step/- \\ $\Delta H_{\text {ads }} \quad$ Enthalpy of adsorption of step $1 / \mathrm{kJ} \mathrm{mol}^{-1}$ \\ I Current/A \\ $k_{i} \quad$ Reaction constant for the ith step $/ \mathrm{s}^{-1}$ \\ $N_{\mathrm{A}} \quad$ Avogadro constant $\left(6.022 \times 10^{23} \mathrm{~mol}^{-1}\right)$ \\ $n_{\mathrm{e}} \quad$ Number of exchanged electrons/- \\ $N_{\max } \quad$ Maximal number of the reaction sites on the \\ surface/- \\ $Q_{\mathrm{CO}} \quad$ CO charge calculated by use of a model/C \\ $Q_{\mathrm{m}} \quad$ Charge for formation of a monolayer of \\ monovalent adsorbed species/C \\ $r_{i} \quad$ Reaction rate for the ith step/ $\mathrm{s}^{-1}$ \\ $\mathrm{R} \quad$ Universal gas constant/J mol ${ }^{-1} \mathrm{~K}^{-1}$ \\ $\left(8.314 \mathrm{~J} \mathrm{~mol}^{-1} \mathrm{~K}^{-1}\right)$ \\ $S \quad$ CO surface area $/ \mathrm{cm}^{2}$ \\ $S_{\text {XRD }} \quad$ Specific surface area $/ \mathrm{m}^{2} \mathrm{~g}^{-1}$ \\ $t \quad$ Time/s \\ $T \quad$ Temperature/K \\ wt Weight fraction/- \\ $x_{i} \quad$ Atomic fraction of Pt or Ru atoms on the surface/- \\ $\alpha_{i} \quad$ Charge transfer coefficient for the ith step/-
}


$\beta_{i} \quad$ Symmetry factor for the ith step/-

$\varepsilon_{\mathrm{CO}} \quad$ Model predicted $\mathrm{CO}$ charge up to half peak potential/-

$\varepsilon_{\text {rel }} \quad$ Relative CO charge error/-

$\theta_{i} \quad$ Surface coverage of different species on the surface/-

$\theta_{\max } \quad$ Angle at the $\mathrm{X}$-ray diffraction peak maximum $/ \mathrm{rad}$

$\lambda \quad$ Wavelength of X-ray/nm (here $0.1541874 \mathrm{~nm}$ )

$v \quad$ Sweep rate/ $/ \mathrm{V} \mathrm{s}^{-1}$

$\rho \quad$ Density $/ \mathrm{g} \mathrm{cm}^{-3}$

$\chi \quad$ Molar fraction/-

\section{Subscripts}

$1 \quad \mathrm{OH}$ adsorption reaction

$-1 \quad \mathrm{OH}$ desorption reaction

$\mathrm{CO} \quad$ Refers to $\mathrm{CO}$ adsorbed on the surface

$\mathrm{OH} \quad$ Refers to $\mathrm{OH}$ adsorbed on the surface

2_Pt Surface reaction on platinum (step 2)

2_Ru Surface reaction on ruthenium (step 2)

CO_Pt CO adsorbed on platinum

CO_Ru CO adsorbed on ruthenium

DL Double layer

$I=I_{\mathrm{p} / 2} \quad$ Half peak potential

$\mathrm{Pt} \quad$ Platinum

$\mathrm{PtRu} \quad$ Platinum ruthenium alloy

$\mathrm{Ru} \quad$ Ruthenium

\section{Introduction}

The CO oxidation on the surface of noble metal catalysts (platinum or platinum ruthenium) is a well studied reaction due to its relative simplicity and its use as a model reaction in both experimental and theoretical studies [1,2]. It has also a great relevance in applied studies, since $\mathrm{CO}$ acts as a poison in a Polymer Electrolyte Membrane (PEM) fuel cell $[3,4]$, and is an intermediate generated during methanol oxidation in the Direct Methanol Fuel Cell (DMFC) [5].

During the oxidation $\mathrm{CO}$ can be present in the solution (gas stream) $[3,4,6]$ or only on the surface $[1,7]$. The first case is important for studying the influence of $\mathrm{CO}$ adsorption and oxidation on the kinetics of the hydrogen oxidation in PEM fuel cell and for optimising the performance of a reactor for preferential electrochemical $\mathrm{CO}$ removal [8]. The second case is of importance in fundamental studies which use the $\mathrm{CO}$ oxidation reaction for surface characterisation [1] and in both fundamental and applied studies which use CO oxidation for the determination of the electrochemically active surface area [7, 9].

In the present study the oxidation of $\mathrm{CO}$ adsorbed on the surface is investigated. In principle $\mathrm{CO}$ adsorbed on the surface can be oxidised in a stripping scan or in a potential step. Both possibilities have been well studied in literature and there is a vast of experimental and theoretical data $[1,2,7,9-11]$. Here the removal of $\mathrm{CO}$ adsorbed on the surface in a stripping scan is investigated. The $\mathrm{CO}$ stripping voltammetry is chosen since it is very often used in most experimental studies for the determination of the surface area of PtRu catalysts, e.g. [12]. This method is very promising, but it has many uncertainties (the main one is the $\mathrm{CO}$ charge correction in respect to other contributions, like double layer charging and charging due to metal oxide formation, i.e. a baseline subtraction), which were already discussed in literature [13]. In our recent paper [14] different strategies for baseline subtraction were tested and an empirical approach for an "accurate" surface area determination of PtRu catalyst in a membrane electrode assembly was suggested. This method uses only the beginning part of the $\mathrm{CO}$ stripping peak, assuming to be free of other faradaic (like oxide formation) and non-faradaic contributions (like double layer charging) and thus enables the accurate surface area determination. In the present paper a model of $\mathrm{CO}$ oxidation together with experimental data (oxidation of saturated $\mathrm{CO}$ monolayer at different sweep rates in the range from 2 to $100 \mathrm{mV} \mathrm{s}^{-1}$ at constant temperature $\left(60^{\circ} \mathrm{C}\right)$ and at different temperatures (room $-60^{\circ} \mathrm{C}$ ) ) is presented. The aim is to further validate the empirical approach suggested in [14]. The formulated model is based on the Langmuir-Hinshelwood mechanism [15]. This mechanism assumes two reaction steps:

1. water dissociative adsorption and

2. surface reaction between $\mathrm{CO}$ and $\mathrm{OH}$ on the surface.

The assumption was made that the water dissociative adsorption is in equilibrium. The rate determining step was assumed to be the surface reaction between $\mathrm{CO}$ and $\mathrm{OH}$ being adsorbed on the surface. Two different kinetic expressions are formulated assuming that the surface reaction is controlled either by an electrochemical or a chemical reaction step. The CO stripping curve is modelled at different sweep rates and at different temperatures. Then, the optimised curves are deconvoluted to partial contributions. Thereby, by means of the mathematical model the charge due to $\mathrm{CO}$ oxidation is calculated and the catalyst surface area is estimated.

\section{Experimental}

All experiments were performed with a Johnson Matthey carbon-supported PtRu catalyst. The total metal loading was $30 \mathrm{wt} \%$ and the Pt:Ru atomic ratio was $1: 1$. The catalyst was applied to a gold substrate $(0.5 \mathrm{~cm}$ diameter $)$ in the form of a thin film [16]. A suspension of the catalyst with $30 \mathrm{wt} \% \mathrm{PtRu}$ was made by mixing $1 \mathrm{ml}$ of water and $3.52 \mathrm{mg}$ of the $\mathrm{PtRu} / \mathrm{C}$ powder. The solution was agitated in an ultrasonic bath for $60 \mathrm{~min}$, and $10 \mu \mathrm{l}$ of it were 
placed on the gold electrode by a micropipette. The drop was dried in a stream of argon for $2 \mathrm{~h}$ at room temperature and then $10 \mu \mathrm{l}$ of $5 \%$ Nafion ${ }^{\circledR}$ solution was placed over the layer of the catalyst and left to dry overnight. This procedure leads to reproducible electrode behaviour.

All experiments were performed in a three compartment glass cell with a gold rotating disk electrode (Radiometer analytical) as working electrode and a Pt-wire as a counter electrode. The metal loading on the electrode surface was $53.9 \mu \mathrm{g} \mathrm{cm}^{-2}$. The reference electrode was a saturated calomel electrode (SCE), but all electrode potentials in the following text were recalculated with respect to standard hydrogen electrode (SHE). The cell was thermostated by the use of a Julabo thermostat with a precision of $\pm 0.1{ }^{\circ} \mathrm{C}$. The supporting electrolyte was $1 \mathrm{M}$ sulphuric acid (Merck, extra pure) and all solutions were prepared using ultra pure water (Millipore, $18 \mathrm{M} \Omega \mathrm{cm}$ ).

$\mathrm{CO}$ was pre-adsorbed on the surface at a constant potential $(0.094 \mathrm{~V})$ and at a constant temperature by purging 0.1 vol\% CO in Argon through the cell. Before CO adsorption on the surface the electrode was conditioned by potential cycling $(60$ cycles between 0.05 and $0.8 \mathrm{~V}$ starting at the open circuit potential). During CO adsorption the electrode was rotated at 2,500 rpm. By performing the $\mathrm{CO}$ adsorption at different adsorption times it was obtained that a saturated $\mathrm{CO}$ monolayer is formed after $60 \mathrm{~min}$. Therefore, all measurements in the present communication were performed after saturated $\mathrm{CO}$ layer has been formed on the surface. After the $\mathrm{CO}$ adsorption the cell was purged with nitrogen $(99.9999 \%$ purity) for $15 \mathrm{~min}$ and then the CO stripping scan was performed. In order to ensure that the $\mathrm{CO}$ was completely removed from the surface two more scans were applied.

All electrochemical measurements were carried out with a Zahner impedance measurement unit (IM6e).

X-ray diffraction (XRD) data of the catalyst were obtained on an X'PERT-PRO diffractometer from Pananalytical GMBH. The scan range was from $10^{\circ}$ to $90^{\circ}$ with a step size of $0.0084^{\circ}$ and a counting time of $19.685 \mathrm{~s}$. The wavelength of X-ray was $1.541874 \mathrm{~nm}$. The measurements were performed at a constant irradiated length of $15.0 \mathrm{~mm}$. As a reference sample the standard reference material (NIST 660a) was used.

\section{Results and discussion}

\subsection{Particle size determination}

In order to get some estimation of the maximal surface area, an ex-situ particle size determination was performed by means of X-ray diffraction (XRD) and the average particle size is further used for the XRD surface area determination (Eq. 2). The average particle size was determined from the broadening of the peak at a position close to the $\mathrm{Pt}(220)$ peak by using the Scherrer equation:

$d=\frac{0.89 \cdot \lambda}{\left(B_{2 \theta}-B_{2 \theta}^{\mathrm{r}}\right) \cdot \theta_{\max }}$

where $d$ is the average particle size in $\mathrm{nm}, \lambda$ the wavelength of X-ray $(0.1541874 \mathrm{~nm}), \theta_{\max }$ the angle at the peak maximum, $B_{2 \theta}$ the width (in rad) of the peak at half height and $B_{2 \theta}^{\mathrm{r}}$ the width (in rad) of the peak at half height for the diffractogram of a standard compound in the similar $2 \theta$ range. $B_{2 \theta}$ has a value of $4.048^{\circ}\left(7.06 \times 10^{-2} \mathrm{rad}\right)$ and $B_{2 \theta}^{\mathrm{r}}$ a value of $0.067^{\circ}\left(1.17 \times 10^{-3} \mathrm{rad}\right)$. The average particle size determined from Eq. 1 is $2.4 \mathrm{~nm}$.

Assuming that the particles are spherical, the maximal specific surface area was calculated by using the equation:

$S_{\mathrm{XRD}}=\frac{6 \times 10^{3}}{\rho_{\mathrm{PtRu}} \cdot d}$

where $S_{\mathrm{XRD}}$ is the specific surface area in $\mathrm{m}^{2} \mathrm{~g}^{-1}, \rho_{\mathrm{PtRu}}$ is PtRu density in $\mathrm{g} \mathrm{cm}^{-3}$ and $d$ is the particle diameter in $\mathrm{nm}$. The PtRu density was calculated as follows:

$\rho_{\mathrm{PtRu}}=\rho_{\mathrm{Pt}} \cdot \chi_{\mathrm{Pt}}+\rho_{\mathrm{Ru}} \cdot \chi_{\mathrm{Ru}}$

where $\rho_{\mathrm{Pt}}$ is the platinum density $\left(21.4 \mathrm{~g} \mathrm{~cm}^{-3}\right), \rho_{\mathrm{Ru}}$ is the ruthenium density $\left(12.2 \mathrm{~g} \mathrm{~cm}^{-3}\right)$ and $\chi_{\mathrm{Pt}}$ and $\chi_{\mathrm{Ru}}$ are molar fractions of $\mathrm{Pt}$ and $\mathrm{Ru}$ in the catalyst without carbon. The latter values are calculated assuming that the Pt:Ru atomic ratio is $1: 1$ ( 0.5 and 0.5 for $\mathrm{Pt}$ and $\mathrm{Ru}$, respectively). The calculated PtRu density $\left(\rho_{\mathrm{PtRu}}\right)$ has a value of $16.8 \mathrm{~g} \mathrm{~cm}^{-3}$ and the specific surface area calculated by Eq. 2 is $148.8 \mathrm{~m}^{2} \mathrm{~g}^{-1}$.

Taking into account that $10 \mu \mathrm{l}$ of $3.52 \mathrm{mg} \mathrm{cm}^{-3}$ of $30 \%$ $\mathrm{PtRu} / \mathrm{C}$ were applied onto gold substrate the expected maximal surface area of the catalyst is $15.8 \mathrm{~cm}^{2}$.

\subsection{The mechanism of $\mathrm{CO}$ stripping}

The $\mathrm{CO}$ oxidation reaction on noble metal surfaces is generally accepted to be of Langmuir-Hinshelwood type with the overall mechanism represented by the following steps [15]:

$$
\begin{aligned}
& \text { Step 0: } \mathrm{CO}(\mathrm{g}) \rightarrow \mathrm{CO}_{\mathrm{ads}} \\
& \text { Step 1: } \mathrm{H}_{2} \mathrm{O} \leftrightharpoons \mathrm{OH}_{\mathrm{ads}}+\mathrm{H}^{+}+\mathrm{e}^{-} \\
& \text {Step 2: } \mathrm{CO}_{\mathrm{ads}}+\mathrm{OH}_{\mathrm{ads}} \rightarrow \mathrm{COOH}_{\mathrm{ads}} \rightarrow \mathrm{CO}_{2}+\mathrm{H}^{+}+\mathrm{e}^{-}
\end{aligned}
$$

The step 0 in the reaction mechanism is the $\mathrm{CO}$ adsorption on the catalyst surface. The kinetics of step 0 is not considered in the model, since the $\mathrm{CO}$ was pre-adsorbed on the surface (saturated CO coverage). The step 1 is water dissociative adsorption. The $\mathrm{OH}$ adsorbed on the surface formed in step 1 is consumed in step 2 (surface reaction 
between $\mathrm{CO}$ and $\mathrm{OH}$ adsorbed on the surface). The step 2 in the mechanism can be decomposed into two steps and the possibility of $\mathrm{COOH}_{\mathrm{ads}}$ formation can be considered.

To analyse the CO removal from the surface in the stripping scan a non-linear mathematical model, based on reactions described by step 1 and step 2 above, was developed. The following model assumptions were made:

(i) A mean field approximation was assumed. The assumption is that the $\mathrm{CO}$ and $\mathrm{OH}$ diffusion rates are much higher than the reaction rate of $\mathrm{CO}$ and the $\mathrm{OH}$ surface reaction. It is assumed that the reactants are homogeneously distributed on the surface (due to the fast diffusion) and that the reaction rate is proportional to the product of $\mathrm{CO}$ and $\mathrm{OH}$ average coverage.

(ii) The CO is linearly bonded. Cuesta et al. [17] have shown that on a polycrystalline $\mathrm{Pt}$ electrode $\mathrm{CO}$ is predominately linearly bonded, while only a small fraction is bridge bonded $\mathrm{CO}$. The ratio between these two species depends on the $\mathrm{CO}$ adsorption potential and the quantity of latter species decreases with increasing $\mathrm{CO}$ adsorption potential. Similar was obtained in a Lin et al. study [18] where CO oxidation on a Ru-modified Pt(111) electrode was studied. The practical consequence of the assumption above is that one $\mathrm{CO}$ molecule blocks one surface site and that upon $\mathrm{CO}$ oxidation two surface sites are set free (the other surface site is occupied by adsorbed $\mathrm{OH}$ ).

(iii) The probability of CO adsorption on both Pt and Ru is the same. This assumption is in accordance to the results of several experimental studies [9, 19, 20]. Bock et al. [20] used the combination of $(\mathrm{COOH})_{2}$ oxidation and $\mathrm{CO}$ stripping to estimate the number of $\mathrm{CO}$ molecules which adsorb on PtRu catalysts with different $\mathrm{Pt}: \mathrm{Ru}$ ratio and they obtained that the probability of $\mathrm{CO}$ to adsorb on both $\mathrm{Pt}$ and $\mathrm{Ru}$ is the same. Wang et al. [9] have shown that for $\mathrm{PtRu}_{20}$ catalysts (Pt:Ru atomic ratio is 1:20) the $\mathrm{CO}$ saturated coverage is 0.66 . This value is between the expected $\mathrm{CO}$ monolayer coverage on a $\mathrm{Pt}(111)$ surface (0.75) and the $\mathrm{CO}$ monolayer coverage on $\mathrm{Ru}(0001)$ surface $(0.5-0.67)$. Therefore the value is in the expected range for a mixed PtRu surface.

(iv) Water dissociative adsorption (step 1) is in equilibrium [21].

(v) The water preferential adsorbs at $\mathrm{Ru}$ surface sites. The dissociation of water at the $\mathrm{Ru}$ sites induces co-adsorption of water at a neighbouring Pt sites. In this way the hydroxyl intermediate can diffuse on the surface. This assumption is in correspondence to the findings of Desai and Neurock [22]. They investigated the interaction of water with a PtRu surface. The initial water dissociation at Ru surface sites leads to the formation of a solvated proton and a surface hydroxyl intermediate centred at the initial $\mathrm{Ru}$ adsorption sites. This process induces further coadsorption of water at a neighbouring $\mathrm{Pt}$ sites. The $\mathrm{OH}$ intermediate at the $\mathrm{Ru}$ sites abstracts a proton from the water which has adsorbed on the Pt-site. As a result the $\mathrm{Ru}-\mathrm{OH}$ is converted to $\mathrm{Ru}-\mathrm{H}_{2} \mathrm{O}$, whereas the Pt-water is converted to $\mathrm{Pt}-\mathrm{OH}$. In this way the hydroxyl intermediate can diffuse on the surface [22] and can be considered to be homogeneously distributed on the surface. This assumption is valid for well-mixed Pt:Ru surfaces, which corresponds to a kind of catalyst used in the present study (Pt:Ru 1:1). As a result of this assumption, only reaction constants for the water dissociative adsorption on $\mathrm{Ru}$ are considered. The rate of $\mathrm{OH}$ surface diffusion (from $\mathrm{Ru}$ to $\mathrm{Pt}$ ) was assumed to be fast.

(vi) The anion adsorption and desorption was not taken into consideration. Cuesta et al. [17] have found that the influence of anion adsorption becomes significant at more positive potentials where most of the $\mathrm{CO}$ is already stripped from the surface and the competition between anions and $\mathrm{OH}$ for the adsorption sites starts to take place [17].

(vii) The surface reaction was assumed to be an irreversible reaction. For the surface reaction two rate constants are assumed. One rate constant corresponds to the oxidation of $\mathrm{CO}$ adsorbed on $\mathrm{Pt}$ and another to the oxidation of $\mathrm{CO}$ adsorbed on $\mathrm{Ru}$. This assumption is in accordance to Fourier Transform Infra Red (FTIR) spectroscopy study of CO adsorbed at PtRu catalyst [23] which showed the presence of different CO IR bands assigned to CO adsorbed on $\mathrm{Pt}$ and $\mathrm{CO}$ adsorbed on $\mathrm{Ru}$.

Based on the assumptions listed above, balance equations for the surface coverage of the $\mathrm{CO}$ and $\mathrm{OH}$ adsorbed on the surface are formulated:

$$
\begin{aligned}
& \frac{d \theta_{\mathrm{OH}}}{d E}=\frac{1}{v} \cdot\left(r_{\mathrm{OH} \_1}-r_{\mathrm{OH} \_-1}-r_{\mathrm{CO} \_\mathrm{Pt}}-r_{\mathrm{CO} \_\mathrm{Ru}}\right) \\
& \frac{d \theta_{\mathrm{CO} \_\mathrm{Pt}}}{d E}=-\frac{1}{v} \cdot r_{\mathrm{CO} \_\mathrm{Pt}} \\
& \frac{d \theta_{\mathrm{CO} \_\mathrm{Ru}}}{d E}=-\frac{1}{v} \cdot r_{\mathrm{CO} \_\mathrm{Ru}}
\end{aligned}
$$

where $v$ is the sweep rate and $r_{\mathrm{OH}_{-} 1}$ is the rate of $\mathrm{OH}$ adsorbed formation (step 1 in the reaction mechanism, forward reaction). It is given by:

$$
\begin{aligned}
r_{\mathrm{OH} \_1}= & k_{1} \cdot\left(1-\theta_{\mathrm{OH}}-\theta_{\mathrm{CO} \_\mathrm{Pt}}-\theta_{\mathrm{CO} \_\mathrm{Ru}}\right) \\
& \cdot \exp \left[\frac{\alpha_{1} \cdot \mathrm{F} \cdot E(t)}{\mathrm{R} \cdot T}\right] .
\end{aligned}
$$


By $r_{\mathrm{OH}_{-}-1}$ the rate of $\mathrm{OH}$ adsorbed desorption (step 1 in the reaction mechanism, backward reaction) is denoted:

$r_{\mathrm{OH}_{-}-1}=k_{-1} \cdot \theta_{\mathrm{OH}} \cdot \exp \left[-\frac{\left(1-\alpha_{1}\right) \cdot \mathrm{F} \cdot E(t)}{\mathrm{R} \cdot T}\right]$

$r_{\mathrm{CO} \_\mathrm{Pt}}$ denotes the rate of $\mathrm{CO}$ oxidation on platinum:

$r_{\mathrm{CO} \_\mathrm{Pt}}=k_{2 \_} \_\mathrm{Pt} \cdot \theta_{\mathrm{OH}} \cdot \theta_{\mathrm{CO} \_\mathrm{Pt}} \cdot \exp \left[\frac{\alpha_{2} \_\mathrm{Pt}}{\mathrm{R} \cdot \mathrm{F} \cdot E(t)}\right]$

and $r_{\mathrm{CO} \_ \text {Ru }}$ the rate of $\mathrm{CO}$ oxidation on ruthenium:

$r_{\mathrm{CO} \_\mathrm{Ru}}=k_{2} \_\mathrm{Ru} \cdot \theta_{\mathrm{OH}} \cdot \theta_{\mathrm{CO} \_\mathrm{Ru}} \cdot \exp \left[\frac{\alpha_{2 \_\mathrm{Ru}} \cdot \mathrm{F} \cdot E(t)}{\mathrm{R} \cdot T}\right]$

The meaning of the other symbols is as usual, i.e. $\theta_{\mathrm{OH}}$, $\theta_{\mathrm{CO} \_\mathrm{Pt}}, \theta_{\mathrm{CO} \_ \text {Ru }}$ are $\mathrm{OH}$ and $\mathrm{CO}$ adsorbed on platinum and on ruthenium surface coverages, $\alpha_{i}$ are the transfer coefficients, $\mathrm{F}$ is Faraday's constant, $E(t)$ the electrode potential, $\mathrm{R}$ the universal gas constant and $T$ the temperature. The surface coverage $\theta_{\mathrm{CO} \_\mathrm{Pt}}$ refers to the total surface, that is $\theta_{\mathrm{CO} \_\mathrm{Pt}}=x_{\mathrm{Pt}} \cdot \theta_{\mathrm{CO} \_\mathrm{Pt}}^{\prime}$, where $x_{\mathrm{Pt}}$ is the atomic fraction of $\mathrm{Pt}$ atoms on the surface, and $\theta_{\mathrm{CO} \_\mathrm{Pt}}^{\prime}$ is the "usual" surface coverage, determined as the ration between the occupied platinum surface sites and the total number of platinum surface sites. Similarly $\theta_{\mathrm{CO} \_ \text {Ru }}$ is defined. The electrode potential is scanned linearly with time $t$, at a sweep rate $v$, starting from initial potential $\left(E_{\text {ini }}\right)$ (here the initial potential is the $\mathrm{CO}$ adsorption potential). The dependence of the electrode potential on time is given by the equation: $E(t)=E_{\text {ini }}+v \cdot t$. The unit of the $k_{i}$ constants (Eqs. 7-10) is $\mathrm{s}^{-1}$ since they include the number of $\mathrm{H}_{2} \mathrm{O}$ and $\mathrm{H}^{+}$ molecules (constants $k_{1}$ and $k_{-1}$, respectively) and the total number of the available surface sites (constants $k_{2} \_\mathrm{Pt}$ and $k_{2} \_\mathrm{Ru}$ ). The number of $\mathrm{H}_{2} \mathrm{O}$ and $\mathrm{H}^{+}$molecules which are involved in step 1 in the reaction mechanism showed above was assumed to be constant and therefore was included in the reaction constants $\left(k_{1}\right.$ and $\left.k_{-1}\right)$.

The current due to $\mathrm{OH}$ formation and consumption (steps 1 and 2) is determined by using the following equation:

$I_{\mathrm{OH}}=Q_{\mathrm{m}} \cdot \frac{d \theta_{\mathrm{OH}}}{d E} \cdot v$

where $Q_{\mathrm{m}}$ is the charge for the formation of a monolayer of monovalent adsorbed species on the catalyst surface. The $Q_{\mathrm{m}}$ charge is equal to:

$Q_{\mathrm{m}}=N_{\max } \cdot \frac{\mathrm{F}}{N_{\mathrm{A}}}$

where $N_{\max }$ is the maximal number of the surface sites, $\mathrm{F}$ is the Faraday constant and $N_{\mathrm{A}}$ is the Avogadro constant. The currents for $\mathrm{CO}$ oxidation on $\mathrm{Pt}$ and $\mathrm{Ru}$ are defined by the following equations:
$I_{\mathrm{CO} \_\mathrm{Pt}}=n_{\mathrm{e}} \cdot Q_{\mathrm{m}} \cdot r_{\mathrm{CO} \_\mathrm{Pt}}$

$I_{\mathrm{CO} \_\mathrm{Ru}}=n_{\mathrm{e}} \cdot Q_{\mathrm{m}} \cdot r_{\mathrm{CO} \_\mathrm{Ru}}$

where $n_{\mathrm{e}}$ is the number of exchanged electrons.

Besides the faradaic currents the double layer charging current was also added to the total $\mathrm{CO}$ stripping current. The double layer charging current was assumed to follow the equation:

$I_{\mathrm{DL}}=v \cdot\left(\left(c_{\mathrm{DL} \_\mathrm{Me}}\right)_{\theta_{\mathrm{CO}=0}}+c_{f} \cdot\left(\theta_{\mathrm{CO} \_\mathrm{Pt}}+\theta_{\mathrm{CO} \_\mathrm{Ru}}\right)\right)$

where $c_{\mathrm{DL} \_\mathrm{Me}}$ is the double layer capacitance of the metal surface in absence of $\mathrm{CO}$ (the same value was assumed for platinum and ruthenium surface $1.87,2.16$ and $2.56 \mathrm{mF}$ at $22,40,60^{\circ} \mathrm{C}$, respectively) and $c_{f}$ is a constant. It is assumed that the double layer capacitance of the metal surface changes linearly with the $\mathrm{CO}$ coverage which is in accordance to [24]. Consequently, the constant $c_{f}$ can be calculated as:

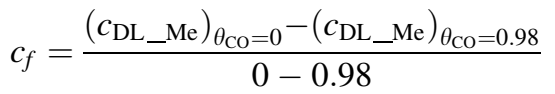

where 0.98 is assumed to be saturated total $\mathrm{CO}$ coverage. The values for the double layer capacitance in absence of $\mathrm{CO}$ and at saturated $\mathrm{CO}$ coverage are determined from the experimental data in the double layer region (app. $0.3 \mathrm{~V}$ ) and in the "hydrogen adsorption/ desorption" region (app. $0.1 \mathrm{~V}$ ), respectively. The following $c_{f}$ values have been calculated: $-1.41,-1.74$ and $-2.11 \mathrm{mF}$ at 22,40 and $60{ }^{\circ} \mathrm{C}$, respectively. The influence of the anion adsorption on double layer capacitance is neglected, while the influence of $\mathrm{OH}$ adsorption is taken into account through the contribution of $I_{\mathrm{OH}}$ current which should roughly correspond to the pseudocapacitive current contribution due to surface oxide formation [25].

The total CO oxidation current is the sum of the partial current contributions:

$I=I_{\mathrm{OH}}+I_{\mathrm{CO} \_\mathrm{Pt}}+I_{\mathrm{CO} \_\mathrm{Ru}}+I_{\mathrm{DL}}$.

The evaluation of $\mathrm{CO}$ charge is done by integration of the surface area under the peak obtained from the contributions of the $\mathrm{CO}$ oxidation currents $\left(I_{\mathrm{CO} \_} \mathrm{Pt}\right.$ and $\left.I_{\mathrm{CO} \_} \mathrm{Ru}_{\mathrm{u}}\right)$.

The $\mathrm{OH}$ and $\mathrm{CO}$ coverages on the surface are obtained by solving the system of balance Eqs. 4-6 (Matlab solver ode15s is used). The $I_{\mathrm{OH}}$ current is obtained by using Eq. 12 while the $\mathrm{CO}$ stripping currents as a function of potential are calculated by using Eqs. 13 and 14. The unknown rate constants are obtained by fitting the calculated curve (Eq. 17) to experimental data. To minimise the deviation between experimental and calculated data the Matlab function $f$ min is used. 
In the following the experimental $\mathrm{CO}$ stripping results will be discussed. Afterwards the simulation results are presented.

\subsection{Analysis of the CO stripping voltammograms}

\subsubsection{Experimental results}

The CO stripping voltammograms of PtRu carbon supported catalyst are collected at different sweep rates $\left(2-100 \mathrm{mV} \mathrm{s}^{-1}\right)$ and at $60{ }^{\circ} \mathrm{C}$. For the sake of clarity only data at one sweep rate $\left(50 \mathrm{mV} \mathrm{s}^{-1}\right)$ are presented (Fig. 1). The shape of the CO stripping peak is in accordance to literature results for similar catalysts [12]. Most of the experimental studies report one peak for $\mathrm{CO}$ stripping on the PtRu catalyst $[12,20]$. In Fig. 1, besides the main CO stripping peak, another much smaller peak appears at more positive potentials and its position changes with the sweep rate (approximately $0.65 \mathrm{~V}$ at $5 \mathrm{mV} \mathrm{s}^{-1}$ and $0.7 \mathrm{~V}$ at $200 \mathrm{mV} \mathrm{s}^{-1}$ ). The $\mathrm{CO}$ is completely removed in the first cycle and the currents in the second cycle coincide with the PtRu base voltammetry (in absence of $\mathrm{CO}$ ).

\subsubsection{Simulation results}

3.3.2.1 Water dissociative adsorption: step 1 The first step in the Langmuir-Hinshelwood mechanism is the water dissociative adsorption. As it was already mentioned this reaction is assumed to be in equilibrium [21]. The next assumption which is made is that Langmuir adsorption conditions are valid for $\mathrm{OH}$ adsorption. However, the Langmuir adsorption for $\mathrm{OH}$ should yield a well-expressed peak in cyclic voltammogram in absence of $\mathrm{CO}$, which is

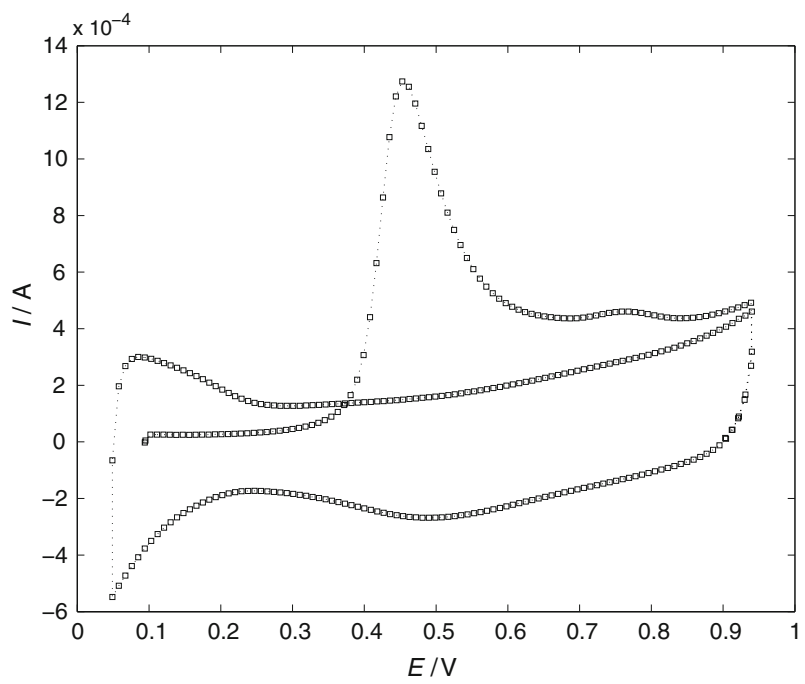

Fig. $1 \mathrm{CO}$ stripping voltammograms of $\mathrm{PtRu} / \mathrm{C}$ catalyst at $50 \mathrm{mV} \mathrm{s}^{-1}$ Conditions: $\mathrm{CO}$ adsorption at $0.094 \mathrm{~V}$ for $60 \mathrm{~min}$, temperature $333.15 \mathrm{~K}, 1 \mathrm{M} \mathrm{H}_{2} \mathrm{SO}_{4}$
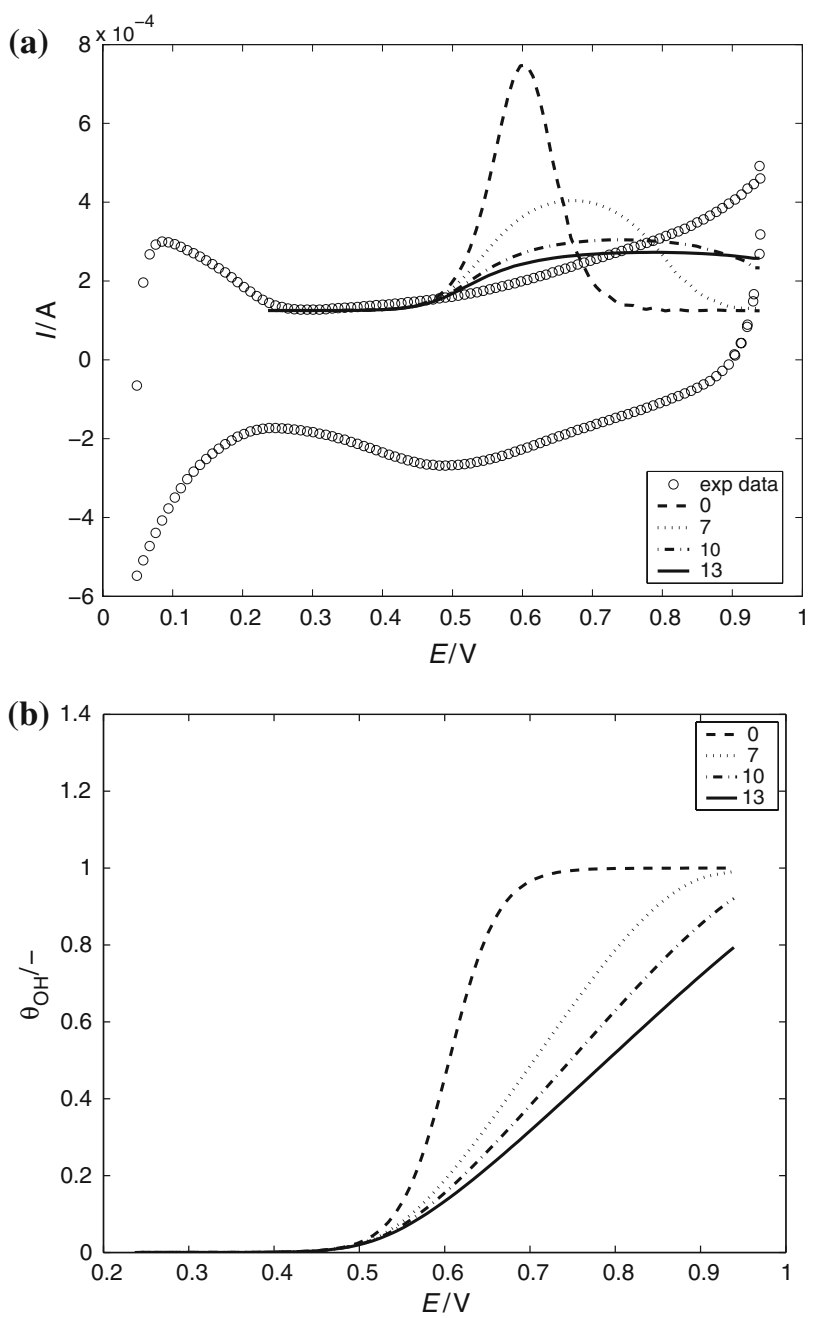

Fig. 2 (a) Experimental cyclic voltammogram of PtRu/C catalyst in absence of $\mathrm{CO}$ and calculated curves (only anodic direction) assuming different $g_{\mathrm{OH}}$ values; (b) Calculated $\mathrm{OH}$ coverage for different $g_{\mathrm{OH}}$ values. Conditions: sweep rate $50 \mathrm{mV} \mathrm{s}^{-1}$, temperature $333.15 \mathrm{~K}$ and $1 \mathrm{M} \mathrm{H}_{2} \mathrm{SO}_{4}$

not observed (Fig. 2a). If the Frumkin/Temkin type of adsorption is assumed the peak which appears in the cyclic voltammogram will be much broader (Fig. 2). The introduction of Frumkin/Temkin adsorption conditions reflects in the reaction constants $k_{1}$ and $k_{-1}$ :

$k_{1}=k_{1,0} \cdot \exp \left[-\beta_{\mathrm{OH}} \cdot g_{\mathrm{OH}} \cdot \theta_{\mathrm{OH}}\right]$

and

$k_{-1}=k_{-1,0} \cdot \exp \left[\left(1-\beta_{\mathrm{OH}}\right) \cdot g_{\mathrm{OH}} \cdot \theta_{\mathrm{OH}}\right]$

where $k_{1,0}$ and $k_{-1,0}$ are intrinsic reaction constants, $\beta_{\mathrm{OH}}$ is a symmetry factor and $g_{\mathrm{OH}}$ is a heterogeneity/interaction factor. The simulation results for step 1, i.e. water dissociative adsorption using Frumkin/Temkin isotherm and assuming different values of heterogeneity/interaction factor $\left(g_{\mathrm{OH}}\right)$ are shown in Fig. 2. The simulated curves (Fig. 2a) are calculated using Eq. 17 and by setting $I_{\text {CO_Pt }}$ 
Table 1 Results of the validation of the models

\begin{tabular}{llll}
\hline & $\begin{array}{l}\text { Variety 1: } \\
\text { chemical r.d.s. }\end{array}$ & $\begin{array}{l}\text { Variety 2: } \\
\text { electrochemical r.d.s. }\end{array}$ & $\begin{array}{l}\text { Variety 1: chemical } \\
\text { r.d.s. (data ref. [7]) }\end{array}$ \\
\hline$k_{1,0} / \mathrm{s}^{-1}$ & $4.00 \times 10^{-4}$ & $4.00 \times 10^{-4}$ & $4.00 \times 10^{-4}$ \\
$k_{-1,0} / \mathrm{s}^{-1}$ & $5.43 \times 10^{5}$ & $5.43 \times 10^{5}$ & $5.43 \times 10^{5}$ \\
$k_{2,0 \_\mathrm{Pt}} / \mathrm{s}^{-1}$ & 8.11 & $6.00 \times 10^{-4}$ & 8.11 \\
$k_{2,0 \_\mathrm{Pt}} / \mathrm{s}^{-1}$ & 22.11 & $6.11 \times 10^{-3}$ & 22.11 \\
$\alpha_{1}$ & 0.5 & 0.5 & 0.5 \\
$\alpha_{2} \_P t$ & 0 & 0.5 & 0 \\
$\alpha_{2} \_$Ru & 0 & 0.5 & 0 \\
$g_{\mathrm{OH}}$ & 13 & 13 & 13 \\
$g_{\mathrm{CO} \_\mathrm{Pt}}$ & 5 & 8 & 5 \\
$g_{\mathrm{CO} \_\mathrm{Ru}}$ & 10 & 10 & 10 \\
$\Delta H_{\mathrm{ads}} / \mathrm{kJ} \mathrm{mol}^{-1}$ & 70.0 & - & 70.0 \\
$E_{a, \mathrm{Pt}} / \mathrm{kJ} \mathrm{mol}^{-1}$ & 20.0 & - & 20.0 \\
$E_{a, \mathrm{Ru}} / \mathrm{kJ} \mathrm{mol}^{-1}$ & 40.0 & - & 40.0 \\
$N_{\text {max }}$ & $9.5 \times 10^{15}$ & $8.5 \times 10^{15}$ & $6.5 \times 10^{15}$ \\
$\theta_{\mathrm{CO} \_\mathrm{Pt}}$ & 0.49 & 0.49 & 0.49 \\
$\theta_{\mathrm{CO} \_ \text {Ru }}$ & 0.49 & 0.49 & 0.49 \\
\hline
\end{tabular}

and $I_{\mathrm{CO} \_ \text {Ru }}$ to zero (CO coverage on the surface is zero). The $\mathrm{OH}$ coverages in Fig. 2b are calculated using Eq. 4 (again due to zero $\mathrm{CO}$ coverage, the reaction rates $r_{\mathrm{CO} \_\mathrm{Pt}}$ and $r_{\mathrm{CO} \_\mathrm{Ru}}$ are equal to zero). The heterogeneity/interaction factor 0 corresponds to Langmuir adsorption conditions. The symmetry factor $\left(\beta_{\mathrm{OH}}\right)$ in the Frumkin/Temkin isotherm is assumed to be 0.5 . The values of the $k_{1,0}$ and $k_{-1,0}$ constants and of the transfer coefficient $\alpha_{1}$ are summarised in Table 1. Further simulations are performed using heterogeneity/ interaction factor 13, since it gives the best approximation of the real conditions.

3.3.2.2 Surface reaction: step $2 \mathrm{CO}$ adsorption conditions: The step 2 is the surface reaction between $\mathrm{CO}$ and $\mathrm{OH}$ adsorbed on the surface. As it was mentioned before this step can be controlled by a chemical reaction (formation of COOHads) or an electrochemical reaction (formation of $\mathrm{CO}_{2}$ ). This makes two model varieties, but before discussing them in details, $\mathrm{CO}$ adsorption conditions on the surface will be discussed. Similar to the $\mathrm{OH}$ adsorption, the change of the $\mathrm{CO}$ adsorption conditions will influence the $k_{2} \_\mathrm{Pt}$ and $k_{2} \_$Ru reaction constants:

$$
\begin{aligned}
k_{2} \_\mathrm{Pt} & =k_{2,0 \_\mathrm{Pt}} \\
& \cdot \exp \left[\beta_{\mathrm{CO} \_\mathrm{Pt}} \cdot g_{\mathrm{CO} \_\mathrm{Pt}} \cdot \theta_{\mathrm{CO} \_\mathrm{Pt}}+\beta_{\mathrm{OH}} \cdot g_{\mathrm{OH}} \cdot \theta_{\mathrm{OH}}\right]
\end{aligned}
$$

$$
\begin{aligned}
k_{2 \_} \_\mathrm{Ru} & =k_{2,0 \_\mathrm{Ru}} \\
& \cdot \exp \left[\beta_{\mathrm{CO} \_\mathrm{Ru}} \cdot g_{\mathrm{CO} \_\mathrm{Ru}} \cdot \theta_{\mathrm{CO} \_\mathrm{Ru}}+\beta_{\mathrm{OH}} \cdot g_{\mathrm{OH}} \cdot \theta_{\mathrm{OH}}\right]
\end{aligned}
$$

The Langmuir adsorption conditions correspond to heterogeneity/interaction factors $\left(g_{\mathrm{CO} \_\mathrm{Pt}}, g_{\mathrm{CO} \_\mathrm{Ru}}\right)$ zero which result in a very sharp $\mathrm{CO}$ stripping peak. In Fig. $3 \mathrm{a}, \mathrm{b}$ the simulation results for $g_{\mathrm{CO} \_\mathrm{Ru}}=0$ (Langmuir adsorption conditions) and different values of $g_{\text {COPt }}(1-10)$ are shown. The $\alpha_{2}$ Pt and $\alpha_{2}$ Ru values are set to zero, since it was assumed that the surface reaction is dominated by the chemical reaction. The water dissociative adsorption is described using the conditions mentioned in Fig. 2 $\left(g_{\mathrm{OH}}=13\right)$. The simulated curves in Fig. 3a are calculated using Eq. 17. As starting $\mathrm{CO}$ coverages, $\theta_{\mathrm{CO} \_\mathrm{Pt}}=$ $\theta_{\mathrm{CO} \_\mathrm{Ru}}=0.49$ are assumed, that the total initial $\mathrm{CO}$ coverage is 0.98 and $x_{\mathrm{Pt}}=x_{\mathrm{Ru}}=0.5$. By increasing of $g_{\mathrm{CO} \_\mathrm{Pt}}$ (Frumkin/Temkin adsorption isotherm) the CO stripping peak is becoming broader and it moves to a more negative potential region. This is due to the additional term of the form exp $\left[\beta_{\mathrm{CO} \_\mathrm{Pt}} \cdot g_{\mathrm{CO} \_\mathrm{Pt}} \cdot \theta_{\mathrm{CO} \_\mathrm{Pt}}+\beta_{\mathrm{OH}} \cdot g_{\mathrm{OH}} \cdot \theta_{\mathrm{OH}}\right]$ in the expression for the rate constant $k_{\mathrm{CO} \_\mathrm{Pt}}$ (Eq. 20), which increases the value of this rate constant and through $\theta_{\mathrm{CO} \_\mathrm{Pt}}$ and $\theta_{\mathrm{OH}}$ introduce an additional dependence on the potential. If the difference between the two rate constants for $\mathrm{CO}$ oxidation on $\mathrm{Pt}$ and $\mathrm{Ru}$ is large enough, one $\mathrm{CO}$ stripping peak will split into two separate peaks. This can be seen in Fig. 3a for interaction/heterogeneity factor 10, where a well expressed shoulder appears. The increase of $g_{\mathrm{CO} \_\mathrm{Pt}}$ moves the onset of $\mathrm{CO}$ oxidation reaction to a more negative potential region.

Two model varieties: The first model variety assumes that the surface reaction is controlled by a chemical reaction. This means that the surface reaction is independent on the potential and formally the transfer coefficients $\alpha_{2}$ Pt and $\alpha_{2} \_$Ru for the surface reaction on Pt and Ru (Eqs. 9 and 10) can be set to zero. The second model variety assumes that the surface reaction is an electrochemical reaction, so here the transfer coefficients $\alpha_{2} \_$Pt and $\alpha_{2} \_$Ru are different 

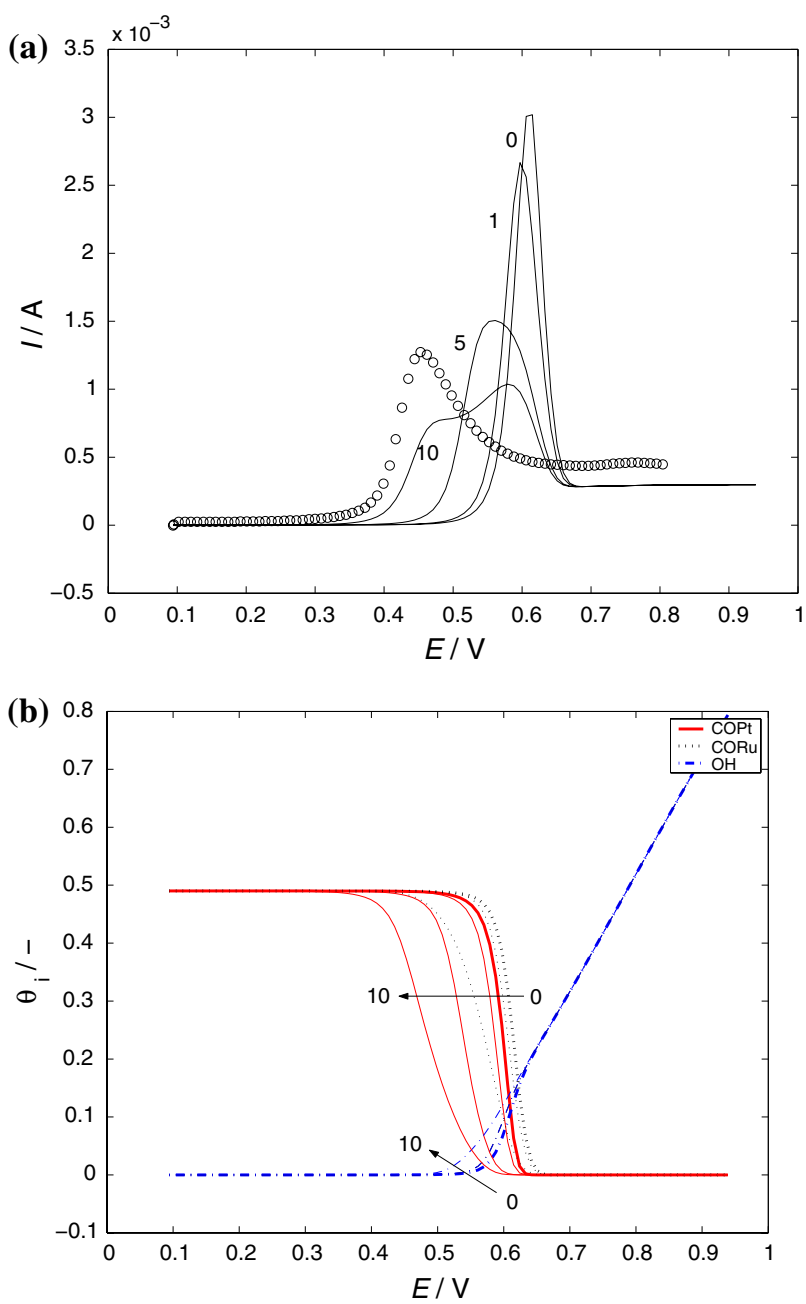

Fig. 3 (a) Experimental CO stripping voltammogram of $\mathrm{PtRu} / \mathrm{C}$ catalyst and calculated curves assuming different $g_{\mathrm{CO} \_\mathrm{Pt}}$ values and constant $g_{\mathrm{CO} \_\mathrm{Ru}}=0$ and $g_{\mathrm{OH}}=13$ values; (b) Calculated $\theta_{\mathrm{OH}}$, $\theta_{\mathrm{CO} \_\mathrm{Pt}}, \theta_{\mathrm{CO} \_\mathrm{Ru}}$ coverages for different $g_{\mathrm{CO} \_\mathrm{Pt}}$ values. Conditions: sweep rate $50 \mathrm{mV} \mathrm{s}^{-1}$, temperature $333.15 \mathrm{~K}$ and $1 \mathrm{M} \mathrm{H}_{2} \mathrm{SO}_{4}$

from zero. The experimental data and the calculated curves for the two model varieties are shown in Fig. 4a, b. In both model varieties the parameter values for the water dissociative adsorption are kept constant and they correspond to the conditions described in Fig. 2. The double layer capacitance and the $c_{f}$ value (Eq. 16) are also kept constant. The transfer coefficients for step 1 and step 2 (surface reaction electrochemical reaction) are assumed to be 0.5 . Also, all symmetry coefficients are assumed to be 0.5 . Other values are fitted such that the simulated curve gives the smallest deviation of the experimental data. The parameter values for two different models are summarised in Table 1. As it can be seen in Table 1 the most pronounced difference between two model varieties is reflected in values of two reaction constants $\left(k_{2} \mathrm{Pt}\right.$ and $\left.k_{2} \mathrm{Ru}\right)$. If the surface reaction is controlled by the electrochemical step the values of these rate constants are
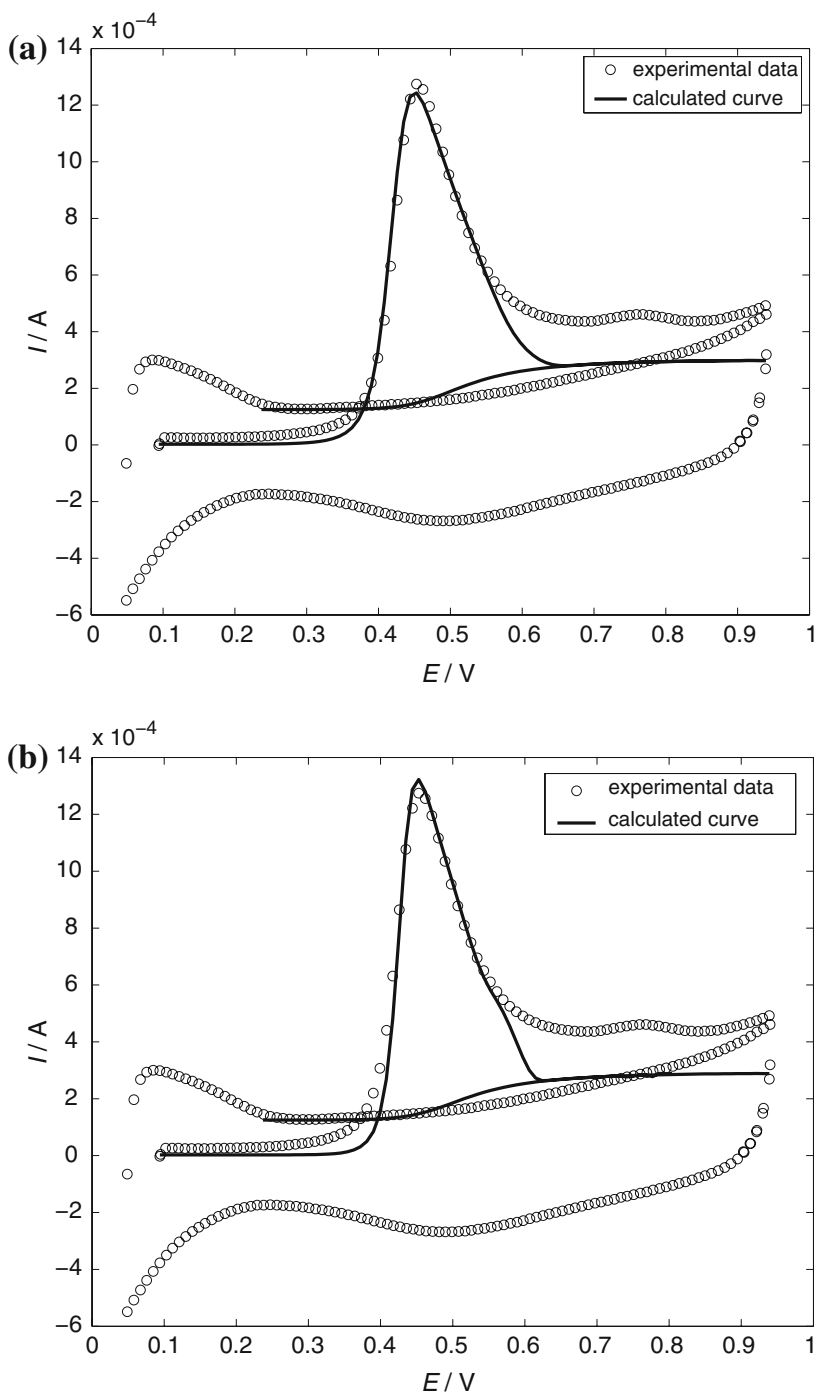

Fig. 4 Experimental $\mathrm{CO}$ stripping cyclic voltammogram (first and second scan) and simulated curves (only anodic direction first and second scan) for (a) model variety 1 and (b) model variety 2 . Conditions: $\mathrm{CO}$ adsorption at $0.094 \mathrm{~V}$ for $60 \mathrm{~min}$, sweep rate $50 \mathrm{mV} \mathrm{s}^{-1}$, temperature $333.15 \mathrm{~K}$ and $1 \mathrm{M} \mathrm{H}_{2} \mathrm{SO}_{4}$. Kinetic parameters from Table 1 (Model varieties 1 and 2)

approximately four orders of magnitude less than in the case of the controlling chemical reaction step. This is understandable taking into account the additional exponential term which appears in the case of the electrochemical reaction. The values of other parameters are very similar (there is only a small difference in the value for heterogeneity factor for $\mathrm{CO}$ adsorbed on $\mathrm{Pt}(5$ (chemical) vs. 8 (electrochemical)) and for the maximal number of surface sites $\left(9.5 \times 10^{15}\right.$ vs. $8.5 \times 10^{15}$ in the case of chemical vs. electrochemical variety) but they are not very significant. In general both model varieties give a reasonable fit to the experimental data. Both model varieties show a deviation in the more positive potential region. Our simulation results predict that in the more positive 
potential region the base curve (in absence of $\mathrm{CO}$ ) coincides with the CO stripping curve. Unlike the model in the experiment an additional charge appears in this potential region. Presently, it is not clear if this charge is a $\mathrm{CO}$ stripping charge or if it is due to some other processes. A possible reason for this deviation can be the very simplified description of the water dissociative reaction (surface oxide formation) which is known to be a more complex reaction and includes a higher oxide formation [25]. Another possibility for this deviation can be the neglection of the anion adsorption in our model, which can take place in the more positive potential region. This assumption is additionally supported by experimental results of Yajima et al. [23] who studied $\mathrm{CO}$ stripping in base electrolyte with a low anion adsorption $\left(\mathrm{HClO}_{4}\right.$, unlike $\mathrm{H}_{2} \mathrm{SO}_{4}$ in our study). In their study the base curve coincides with the $\mathrm{CO}$ stripping curve in the more positive potential region, which is in accordance to our simulation results.

Based on the discussion presented above it is not possible to differentiate between two model varieties. The similar conclusion was reached by Desai and Neurock [22]. They calculated the reaction energies for the $\mathrm{CO}+\mathrm{OH}$ surface reaction for both chemical and electrochemical paths. It was obtained that the difference in the overall reaction energy is insignificant and they concluded that it is difficult to distinguish which of these paths would prevail under electrocatalytic conditions. However the first model variety (chemical reaction) is preferred in the following simulations in accordance to our previous studies where the discrimination between different model varieties in the case of methanol oxidation was performed using electrochemical impedance spectroscopy (EIS) [26].

The influence of sweep rate: The influence of the sweep rate was studied in the sweep rate range between 2 and $100 \mathrm{mV} \mathrm{s}^{-1}$, since this sweep rates were typically used in experimental studies for $\mathrm{CO}$ stripping surface area determination. In Fig. 5a, b the simulated (Model variety 1) and experimental data at different sweep rates are shown. The parameter values are given in Table 1 (Model variety 1). As it can be seen, the agreement between experimental and simulated curves at both low and the high sweep rate is reasonable. The model can predict the sweep rate dependence of the onset, the peak potential, the height of the peak, as well as the peak broadness. As it was discussed before, the model shows a deviation at a more positive potential values, but this point was already discussed above. The height of the peak shows a small deviation at a sweep rate of $10 \mathrm{mV} \mathrm{s}^{-1}$. This deviation can occur due to a small difference in the real catalyst surface area between different experiments. In the model this mostly reflects in $N_{\max }$ (maximal number of surface sites). The influence of the variation of $N_{\max }$ on simulated curves, at the sweep rate of $10 \mathrm{mV} \mathrm{s}^{-1}$ was checked (not shown here). It can be seen
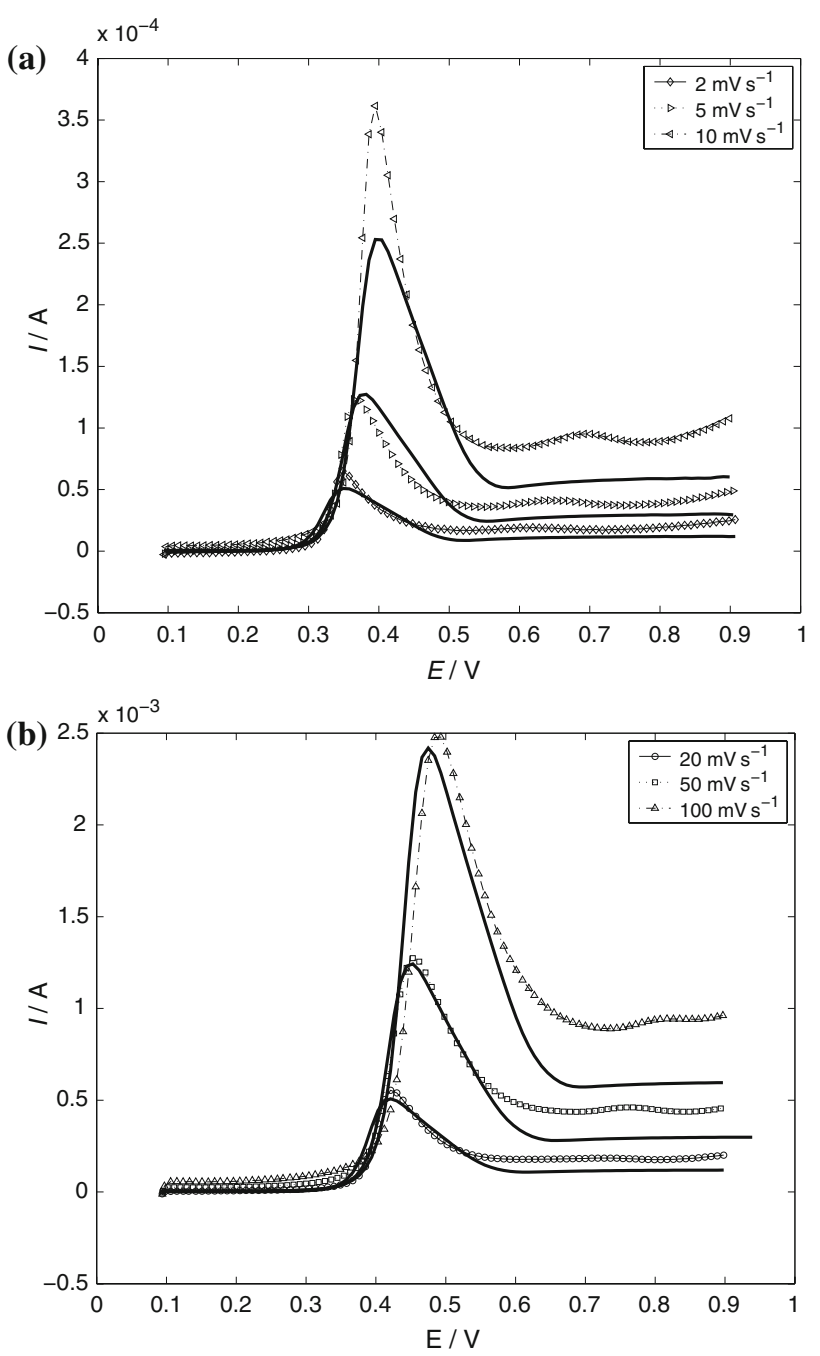

Fig. 5 Experimental (concatenated symbols) and calculated-Model variety 1 (full lines) $\mathrm{CO}$ stripping voltammograms of $\mathrm{PtRu} / \mathrm{C}$ catalyst at different sweep rates. (a) 2, 5, $10 \mathrm{mV} \mathrm{s}^{-1}$ and (b) 20, 50, $100 \mathrm{mV} \mathrm{s}^{-1}$. Conditions: CO adsorption at $0.094 \mathrm{~V}$ for $60 \mathrm{~min}$, temperature $333.15 \mathrm{~K}, 1 \mathrm{M} \mathrm{H}_{2} \mathrm{SO}_{4}$. Kinetic parameters from Table 1 (Model variety 1 )

that the peak height is mainly controlled by $N_{\max }$. Another parameter which can influence the peak height at constant $N_{\max }$ is the CO surface coverage (see Fig. 6b).

The influence of temperature: The CO stripping experiments are performed at different temperatures in the temperature range from 22 (room) to $60{ }^{\circ} \mathrm{C}$ and at the sweep rate of $50 \mathrm{mV} \mathrm{s}^{-1}$. The experimental results are shown in Fig. 6a. The increase of the temperature causes a shift of the CO stripping curve to a lower potential region. The shape of the CO stripping peak is basically unchanged (peak broadness), but the peak height shows some small variations. The cyclic voltammograms in absence of $\mathrm{CO}$ show the difference in the double layer region (app. 0.25$0.3 \mathrm{~V}$ ) and the double layer capacitance increases slightly with the temperature $\left(1.87 \mathrm{mF}\right.$ at $22{ }^{\circ} \mathrm{C}$ and $2.56 \mathrm{mF}$ at 

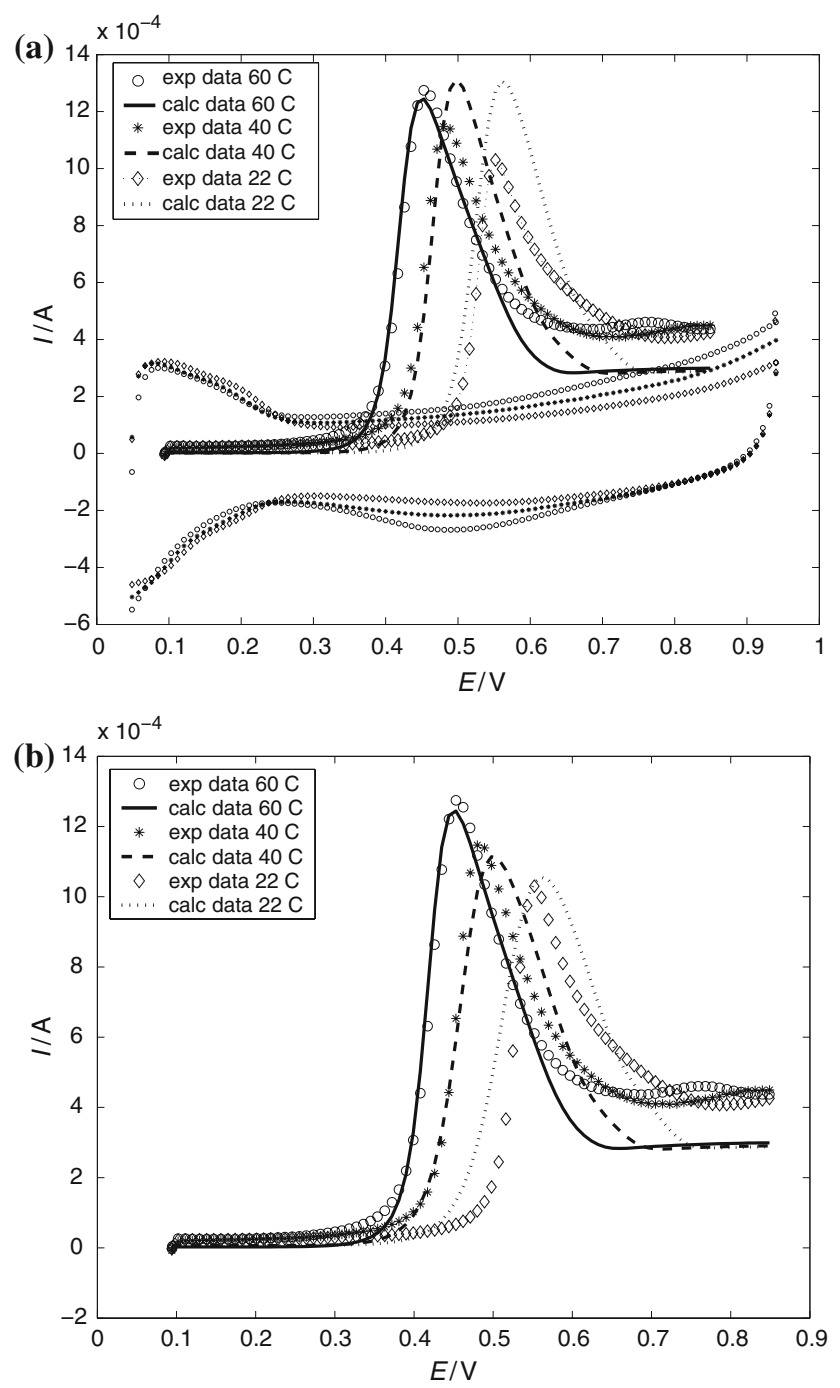

Fig. 6 Experimental and simulated CO stripping voltammograms at different temperatures. (a) Kinetic parameters from Table 1 (Model variety 1). (b) The values of CO coverage is adjusted to fit better the curves at lower temperatures. Other kinetic parameters same as in (a). Conditions: $\mathrm{CO}$ adsorption at $0.094 \mathrm{~V}$ for $60 \mathrm{~min}$, sweep rate $50 \mathrm{mV} \mathrm{s}^{-1}, 1 \mathrm{M} \mathrm{H}_{2} \mathrm{SO}_{4}$

$\left.60{ }^{\circ} \mathrm{C}\right)$. The difference can be also seen in the more positive potential region which is related to the temperature influence on the surface oxide formation. For the model description of the experimental data it is assumed that the rate constants are temperature dependent:

$$
\begin{aligned}
\left(\frac{k_{1,0}}{k_{-1,0}}\right)_{T}= & \left(\frac{k_{1,0}}{k_{-1,0}}\right)_{T=60^{\circ} \mathrm{C}} \\
& \cdot \exp \left[-\frac{\Delta H_{\mathrm{ads}}}{\mathrm{R}}\left(\frac{1}{T}-\frac{1}{273.15+60.0}\right)\right] \\
\left(k_{2,0 \_i}\right)_{T}= & \left(k_{2,0 \_i}\right)_{T=60^{\circ} \mathrm{C}} \\
& \cdot \exp \left[-\frac{E_{a, i}}{\mathrm{R}}\left(\frac{1}{T}-\frac{1}{273.15+60.0}\right)\right]
\end{aligned}
$$

where, $\Delta H_{\mathrm{ads}}$ is the enthalpy of adsorption for the water dissociative adsorption step, $E_{a, i}$ are the activation energies for the surface reaction and $i$ denotes $\mathrm{Pt}$ or $\mathrm{Ru}$. The enthalpy of the adsorption and activation energies are used as additional fitting parameters to fit the experimental $\mathrm{CO}$ stripping curves at different temperatures and their values are given in Table 1 (only for model variety 1 ). For these simulations it is assumed that the heterogeneity/interaction factors, transfer and symmetry coefficients are temperature independent, since the temperature interval is not very large. The enthalpy of adsorption for the water dissociative adsorption has a value of $70.0 \mathrm{~kJ} \mathrm{~mol}^{-1}$. This value has been chosen in order to give a similar shift of the onset potential of $\mathrm{OH}$ adsorption as seen in the cyclic voltammograms in absence of $\mathrm{CO}$ (Fig. 6a). The activation energies for the surface reaction on $\mathrm{Pt}$ and $\mathrm{Ru}$ are 20 and $40 \mathrm{~kJ} \mathrm{~mol}^{-1}$, respectively. As can be seen in Fig. 6a the simulated curves show a good agreement to the experimental data. In the more positive potential region the simulated curves show a deviation in comparison to the experimental data (as it was already discussed), but the tendency predicted by the model is correct. The model predicts a small increase of the peak current with a decrease of temperature, while the experimental curves show an opposite tendency. It was already discussed that the variations in the peak current can be due to small variations in the real surface area which can slightly vary from experiment to experiment (the precision of thin film method [16]) or to some small difference in the CO surface coverage. The second possibility is checked in Fig. 6b, where the curves at room temperature and $40.0{ }^{\circ} \mathrm{C}$ are simulated for a total CO coverage (0.94 and 0.96 , respectively) and a better agreement to experimental data was obtained.

\subsection{The CO stripping peak deconvolution}

As it was mentioned in the introduction we intend to use the calculated $\mathrm{CO}$ stripping curve to perform the $\mathrm{CO}$ stripping peak deconvolution and to separate the $\mathrm{CO}$ stripping charge from other contributions which makes the voltammetric CO charge determination less accurate [13]. The CO stripping peak deconvolution is demonstrated in Fig. 7 for the sweep rate of $50 \mathrm{mV} \mathrm{s}^{-1}$. The simulated curve is calculated by using the model variety 1 . The grey lines (full and dotted line) correspond to the $\mathrm{CO}$ currents and they were used to calculate the $\mathrm{CO}$ charge. The calculated $\mathrm{CO}$ charges at different sweep rates are summarised in Table 2. Taking the $\mathrm{CO}$ charge values, the total CO coverage (0.98) and assuming $420 \mu \mathrm{C} \mathrm{cm}^{-2}$ as an elementary charge for a 2 electron process the real surface area values are determined (Table 2). The mean value of 


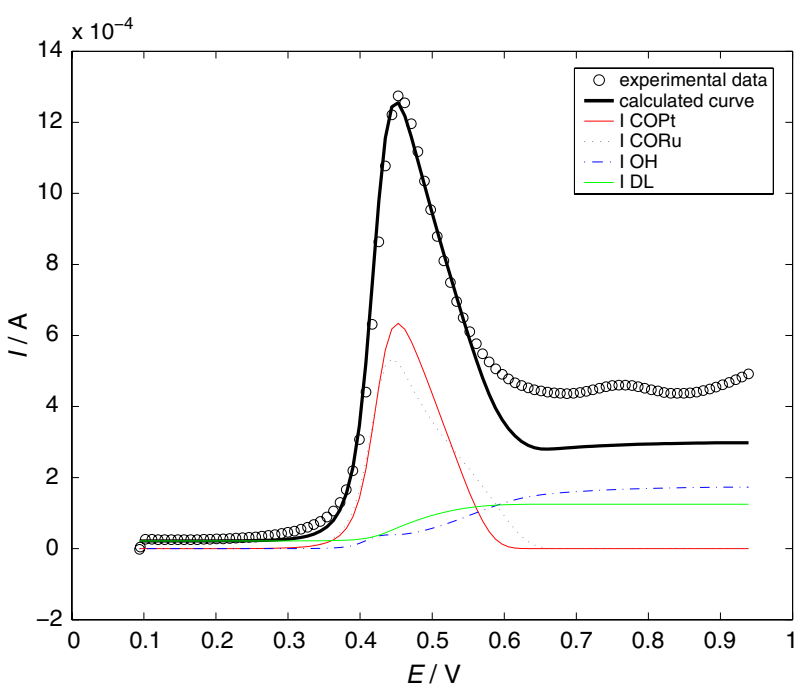

Fig. 7 The $\mathrm{CO}$ stripping peak deconvolution. Conditions: sweep rate $50 \mathrm{mV} \mathrm{s}^{-1}$, temperature $333.15 \mathrm{~K}$ and $1 \mathrm{M} \mathrm{H}_{2} \mathrm{SO}_{4}$. Kinetic parameters from Table 1 (Model variety 1 )

Table 2 Model calculated (Variety 1) relative error, percent of CO charge consumed up to half peak potential and surface area

\begin{tabular}{clll}
\hline Sweep rate $/ \mathrm{mV} \mathrm{s}^{-1}$ & $\varepsilon_{\text {rel }} / \%$ & $\varepsilon_{\mathrm{CO}} / \%$ & $S / \mathrm{cm}^{2}$ \\
\hline 2 & 2.04 & 8.45 & 6.78 \\
5 & 2.37 & 9.7 & 6.72 \\
10 & 2.73 & 8.87 & 6.72 \\
20 & 3.48 & 8.92 & 6.73 \\
50 & 5.53 & 8.89 & 6.72 \\
100 & 8.60 & 8.78 & 6.74 \\
\hline
\end{tabular}

the surface area calculated at different sweep rates is $6.73 \pm 0.03 \mathrm{~cm}^{2}$. The calculated value is only $42 \%$ of XRD surface area $\left(6.73 \mathrm{~cm}^{2}\right.$ in comparison to $\left.15.8 \mathrm{~cm}^{2}\right)$. This result is in agreement to results of other literature studies, which showed a deviation between, e.g. BET and $\mathrm{CO}$ stripping area (e.g. in [7] CO stripping area is approx $45-52 \%$ of BET surface area).

\subsection{Comparison with an empirical method and literature data}

As it was mentioned above, the practical problem in voltammetric $\mathrm{CO}$ charge determination using experimental data is a baseline subtraction. In praxis, it is usually assumed that baseline is the same as in absence of $\mathrm{CO}$, or that it can be approximated by a straight line. Both options can lead to significant deviations between the calculated and the real surface area [7, 14]. In our previous paper an empirical method for "accurate" voltammetric CO charge determination is proposed [14]. This method assumes that the $\mathrm{CO}$ charge at the onset of the $\mathrm{CO}$ stripping curve is not influenced by other faradaic and non-faradaic contributions. If the $\mathrm{CO}$ stripping curve is integrated only up to the half peak potential (assuming that the base line is a linear extension of the CO stripping line), and enlarged approximately for a factor 10 (this was determined in an independent experiment with platinum) the determined charge is independent on the sweep rate. So the main assumptions of our empirical method are:

1. the base line in the potential region up to the half peak potential can be approximated by a straight line, which is the extension of the CO stripping line, and

2. the $\mathrm{CO}$ charge consumed up to the half peak potential is proportional to the total CO stripping charge, and the proportionality factor is independent of the sweep rate.

These two assumptions can be now validated by the proposed mathematical model. In Fig. 8a, b the simulated curves at sweep rates 2 (Fig. 8a) and $100 \mathrm{mV} \mathrm{s}^{-1}$ (Fig. 8b) are presented. The baselines in absence of $\mathrm{CO}$ (dotted line) and in presence of $\mathrm{CO}$ (dashed line) are also shown. The hatched areas in Fig. 8a, b correspond to the CO charge consumed up to the half peak potential. According to the simulated results the baseline in presence of $\mathrm{CO}$ (dashed line) in the potential region up to the half peak potential (hatched area) deviates from linearity at both sweep rates, but the deviation is stronger expressed at higher sweep rates $\left(100 \mathrm{mV} \mathrm{s}^{-1}\right)$. If the baseline is approximated by the straight line (assumption "a") the percent error can be calculated as:

$\varepsilon_{\mathrm{rel}}=\frac{\left(\theta_{\mathrm{CO}, I=I_{\mathrm{p} / 2}}\right)_{\mathrm{approx}}-\left(\theta_{\mathrm{CO}, I=I_{\mathrm{p} / 2}}\right)_{\text {exact }}}{\left(\theta_{\mathrm{CO}, I=I_{\mathrm{p} / 2}}\right)_{\text {exact }}} \cdot 100$

where $\theta_{\mathrm{CO}, I=I_{\mathrm{p} / 2}}$ is the $\mathrm{CO}$ stripping charge consumed up to the half peak potential and the indices approx and exact denote the approximated (straight line) and the real (model calculated) baseline. In the sweep range $2-100 \mathrm{mV} \mathrm{s}^{-1}$ the error $\varepsilon_{\text {rel }}(24)$ is in the range between 2.04 and $8.78 \%$ (the values for different sweep rates are summarised in Table 2). This would mean that for the voltammetric CO charge determination the experimental data at lower sweep rates are more suitable. The ratio of $\mathrm{CO}$ charge consumed up to the half peak potential with respect to the total $\mathrm{CO}$ charge can be calculated as follows:

$\varepsilon_{\mathrm{CO}}=\frac{\theta_{\mathrm{CO}, I=I_{\mathrm{p} / 2}}}{\theta_{\mathrm{CO}, \text { total }}} \cdot 100$

The $\varepsilon_{\mathrm{CO}}$ values at the different sweep rates are presented in Table 2. The mean value is $8.93 \pm 0.41 \%$. According to the model predictions the approximation of the baseline as a straight line can be used with a higher certainty at low sweep rates and the ratio of the $\mathrm{CO}$ charge consumed up to the half peak potential is constant at different sweep rates. 

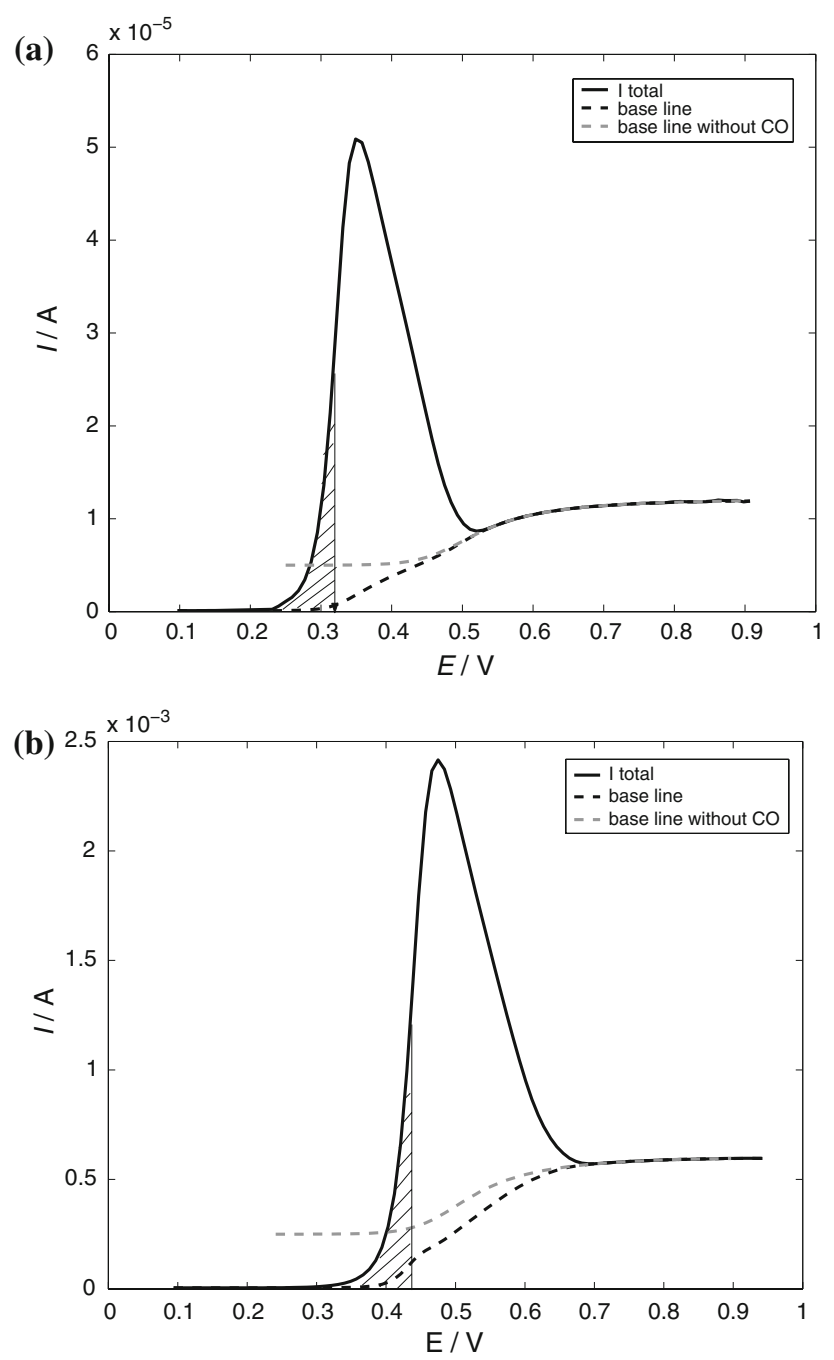

Fig. 8 The influence of sweep rate on the baseline deviation from the linearity in the potential region up to the half peak potential. Simulation results at (a) 2 and (b) $100 \mathrm{mV} \mathrm{s}^{-1}$. Kinetic parameters from Table 1 (Model variety 1)

It can be concluded that the assumptions of the empirical model are reasonable (especially at low sweep rates) and it can be used for reliable experimental $\mathrm{CO}$ voltammetric charge determination.

Finally, our method is compared to literature data [7]. These data are chosen since the $\mathrm{CO}$ charge in [7] was determined by using the differential electrochemical mass spectrometry (DEMS), which should give a better estimation of $\mathrm{CO}$ charge. In Fig. 9 the experimental data from reference [7] and the simulated curves using model variety 1 are shown. The model parameters are summarised in Table 1 and as can be seen they correspond to the parameter values determined from experimental data in the present study. The difference is only in $N_{\max }$. The $N_{\max }$ value is determined from the known real $\mathrm{CO}$ charge value for this catalyst (1.9 mC, DEMS data). As can be seen in Fig. 9 a

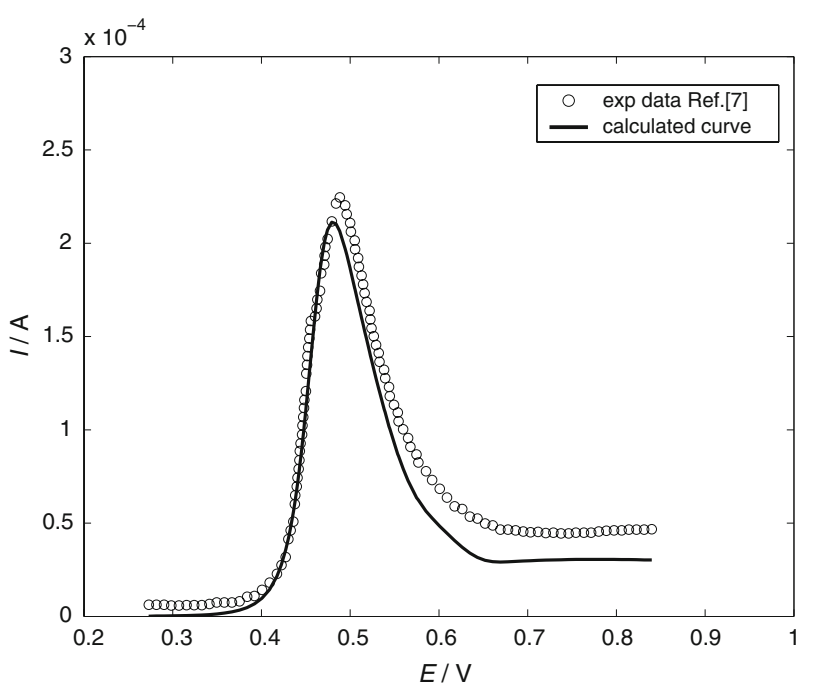

Fig. 9 The experimental (data from ref. 7]) and the simulated CO stripping voltammograms. Conditions: sweep rate $10 \mathrm{mV} \mathrm{s}^{-1}$, temperature $293.15 \mathrm{~K}$. Kinetic parameters from Table 1 (Model variety 1-Data [7])

very good agreement to experimental data is obtained. The deviation is observed only in the more positive potential region, which can be due to anion adsorption neglection as it was already discussed above.

\section{Conclusions}

The determination of the real surface area under working conditions (fuel cell conditions) has a great practical relevance in the fuel cell community (evaluation of the catalyst deuteration under working conditions). The most common solution in daily fuel cell praxis is a surface area determination by use of CO stripping. The method however is not accurate from the reasons discussed above. In this study a mathematical model of $\mathrm{CO}$ stripping voltammetry based on the Langmuir-Hinshelwood mechanism was developed. The model can predict the sweep rate dependence of the onset of $\mathrm{CO}$ oxidation, the peak potential, peak current and peak broadness. The small deviations between the model and the experimental data are observed in the more positive potential region. These deviations can be due to neglection of anion adsorption in the model. The model proposed here enables the $\mathrm{CO}$ stripping peak deconvolution and the separation of the $\mathrm{CO}$ stripping charge from other faradaic and non-faradaic contributions, which is the main difficulty in the voltammetric CO charge determination. The model predicts baseline deviation from linearity, in the potential region up to the half peak potential, at all sweep rates. The deviation is the smallest at $2 \mathrm{mV} \mathrm{s}^{-1}(2.04 \%)$ in comparison to $8.78 \%$ at $100 \mathrm{mV} \mathrm{s}^{-1}$, so the use of low sweep rates for $\mathrm{CO}$ voltammetric charge determination from the 
experimental data is suggested. According to the model, approximately $8.93 \%$ of the total CO charge is consumed up to the half peak potential and this value is not changing with the sweep rate. The above model predictions validate the use of the empirical method proposed in [14] as a practical approach for the $\mathrm{CO}$ stripping charge determination. The real CO stripping charge can be determined by some non-electrochemical methods. An example is DEMS. The experimental results from the literature DEMS study [7] are used for further model validation and a very good agreement is obtained.

Acknowledgments We would like to acknowledge Dr. Heike Lorenz, (Max Planck Institute for Dynamics of Complex Technical Systems in Magdeburg) for performing X-ray catalyst analysis and Mr. Christian Fuchs (Max Planck Institute for Dynamics of Complex Technical Systems in Magdeburg) for making CO stripping measurements.

Open Access This article is distributed under the terms of the Creative Commons Attribution Noncommercial License which permits any noncommercial use, distribution, and reproduction in any medium, provided the original author(s) and source are credited.

\section{References}

1. Gasteiger H, Marković N, Ross P, Cairns E (1994) J Phys Chem 98:617

2. Koper M, Jansen A, Santen R, Lukkien J, Hilbers P (1998) J Chem Phys B 109:6051

3. Camara G, Ticianelli E, Mukerjee S, Lee S, McBreen J (2002) J Electrochem Soc 149(6):A748

4. Behm R, Jusys Z (2006) J Power Sources 154:327
5. Vidaković T, Christov M, Sundmacher K (2005) J Electroanal Chem 580:105

6. Enback S, Lindbergh G (2005) J Electrochem Soc 151(1):A23

7. Jusys Z, Schmidt T, Dubau L, Lasch K, Jorissen L, Garche J, Behm R (2002) J Power Sources 105:297

8. Zhang J, Datta R (2005) J Electrochem Soc 152(6):A1180

9. Wang J, Branković R, Zhu Y, Hanson J, Adzić R (2003) J Electrochem Soc 150(8):A1108

10. Maillard F, Eikerling M, Cherstiouk O, Schreier S, Savinova E, Stimming U (2004) Faraday Discuss 125:357

11. Koper M, Lebedeva N, Hermse G (2002) Faraday Discuss 121:301

12. Dihn H, Ren X, Garzon F, Zelenay P, Gottesfeld S (2000) J Electroanal Chem 491:222

13. Nart F, Vielstich W (2003) Handbook of fuel cells-fundamentals, technology and applications, vol 2. Wiley, Chichester

14. Vidaković T, Christov M, Sundmacher K (2007) Electrochim Acta 52:5606

15. Gilman S (1964) J Phys Chem 68:70

16. Schmidt TJ, Gasteiger HA, Behm RJ (1999) Electrochem Commun 1:1

17. Cuesta A, Couto A, Rincon A, Perez M, Lopez-Cudero A, Gutierrez C (2006) J Electroanal Chem 586:184

18. Lin WF, Zei MS, Eiswirth M, Ertl G, Iwasita T, Vielstich W (1999) J Phys Chem B 103:6968

19. Gasteiger H, Marković N, Ross P, Cairns E (1994) Electrochim Acta 39:1825

20. Bock C, MacDougall B, LePage Y (2004) J Electrochem Soc 151(8):A1269

21. Saravanan C, Marković N, Head-Gordon M, Ross PN (2001) J Chem Phys 114:6403

22. Desai S, Neurock M (2003) Electrochim Acta 48:3759

23. Yajima T, Uchida H, Watanabe M (2004) J Phys Chem B 108:2654

24. Bilmes SA, Arvia AJ (1986) J Electroanal Chem 198:137

25. Trasatti S, O'Grady W (1981) Advances in electrochemistry and electrochemical engineering, vol 12. Wiley, New York

26. Krewer U, Christov M, Vidaković T, Sundmacher K (2006) J Electroanal Chem 589:148 